\title{
MICORRIZA ARBUSCULAR E RIZÓBIOS NO ENRAIZAMENTO E NUTRIÇÃO DE MUDAS DE ANGICO-VERMELHO ${ }^{1}$
}

\author{
Poliana Coqueiro Dias², Muriel da Silva Folli Pereira ${ }^{3}$, Maria Catarina MegumiKasuya ${ }^{4}$, Haroldo
} Nogueira de Paiva ${ }^{5}$, Leandro Silva de Oliveira ${ }^{6}$ e Aloisio Xavier ${ }^{5}$

\begin{abstract}
RESUMO - O objetivo deste estudo foi avaliar o efeito da inoculação dos fungos micorrízicos arbusculares (FMAs) e rizóbio no enraizamento, crescimento e nutrição de mudas de angico-vermelho (Anadenanthera macrocarpa (Benth) Brenan) propagadas via miniestaquia. Foram utilizadas seis progênies, das quais foram confeccionadas miniestacas com um par de folhas inteiras, bem como tubetes de $55 \mathrm{~cm}^{3}$ contendo substrato comercial Bioplant ${ }^{\circledR}$. Foram testados quatro tratamentos: $8 \mathrm{~kg} \mathrm{~m}^{-3}$ de superfosfato simples (SS) misturados ao substrato; $4 \mathrm{~kg} \mathrm{~m}^{-3}$ de SS misturados ao substrato; $4 \mathrm{~kg} \mathrm{~m}^{-3}$ de SS misturados ao substrato e adição de suspensão contendo rizóbios; e $4 \mathrm{~kg} \mathrm{~m}^{-3}$ de SS e adição de suspensão contendo rizóbios e $5 \mathrm{~g}$ de solo contendo esporos de FMAs. Não houve interação entre os tratamentos para percentagem de sobrevivência das miniestacas e percentagem de miniestacas com raízes observadas na extremidade inferior do tubete, na saída da casa de vegetação (30 dias) e da casa de sombra (40 dias), provavelmente em função do sistema radicular ainda estar em formação. Houve diferenças entre as progênies para percentagem de sobrevivência das miniestacas, percentagem de miniestacas com raízes observadas na extremidade inferior do tubete, altura, diâmetro de colo e massa seca da parte aérea. As avaliações das características de crescimento das miniestacas enraizadas, principalmente com relação à sobrevivência a pleno sol (140 dias), evidenciam a eficiência dos rizóbios e FMAs na produção de mudas desta espécie. Conclui-se que a associação simbiótica com rizóbio e/ou FMA favorece a produção de mudas de $A$. macrocarpa via miniestaquia.
\end{abstract}

Palavras-chave: Anadenanthera macrocarpa (Benth) Brenan, Propagação vegetativa, Miniestaquia, Propagação de plantas, FMA, FBN.

\section{ARBUSCULAR MYCORRHIZAE AND RHIZOBIUM IN ROOTING AND NUTRITION OF ANGICO-VERMELHO SEEDLINGS}

\begin{abstract}
The objective of this study was to evaluate the effect of inoculation of arbuscular mycorrhizae fungi (AMF) and rhizobium on rooting, growth and nutrition of seedlings of angico-red (Anadenanthera macrocarpa (Benth) Brenan) propagated by minicutting. Six progenies were used, of which were prepared cuttings with a pair of complete leaves. It was used a $55 \mathrm{~cm}^{3}$ container filled with commercial substrate Bioplant ${ }^{\circledR}$. Four treatments were tested: $8 \mathrm{~kg} \mathrm{~m}-3$ of superphosphate (SS) added to substrate; $4 \mathrm{~kg} \mathrm{m-3} \mathrm{SS} \mathrm{added} \mathrm{to}$ substrate; $4 \mathrm{~kg} \mathrm{m-3} \mathrm{SS} \mathrm{added} \mathrm{to} \mathrm{substrate} \mathrm{and} \mathrm{adition} \mathrm{of} \mathrm{a} \mathrm{suspension} \mathrm{solution} \mathrm{containing} \mathrm{rhizobium;} 4$ $\mathrm{kg} \mathrm{m-3SS}$ and suspension solution containing rhizobium plus $5 \mathrm{~g}$ of soil contaminated by AMF spores. There was no interaction among treatments for survival rate of cuttings and roots observed at bottom of the container, evaluated in the greenhouse exit ( 30 days) and the shade house exit ( 40 days), probably because the root
\end{abstract}

\footnotetext{
${ }^{1}$ Recebido em 11.04.2012 aceito para publicação em 04.06.2012

${ }^{2}$ Pós-Graduação em Ciência Florestal, Universidade Federal de Viçosa, UFV, Brasil. E-mail: <policoqueiro@ yahoo.com.br>.

${ }^{3}$ Pós-Graduação em Microbiologia Agrícola, Universidade Federal de Viçosa, BIOAGRO. E-mail: <mfolli@ gmail.com>.

${ }^{4}$ Centro de Ciências Biológicas e da Saúde, Departamento de Microbiologia, Universidade Federal de Viçosa. E-mail: $<$ mkasuya@ ufv.br $>$.

${ }^{5}$ Departamento de Engenharia Florestal, Universidade Federal de Viçosa. E-mail: <hnpaiva@ufv.br>e <xavier@ufv.br>.

${ }^{6}$ Pós-Graduação em Recursos Florestais, Universidade de São Paulo/Escola Superior de Agricultura "Luiz de Queiroz".

E-mail: <leandrooliveiraufv@yahoo.com.br>
} 


\begin{abstract}
system was still in formation. There were differences among the progeny for survival rate of the shoots, the percentage of cuttings with roots observed at bottom of the container, height, stem diameter and shoot dry weight. The evaluations of the growth characteristics of the cuttings in, particularly with respect to survival at full sun (140 days), demonstrate the efficiency of rhizobium and AMF on seedling production of this species. We conclude that the symbiotic association with rhizobium and / or FMA favors the production of seedlings of A. macrocarpa by minicutting.
\end{abstract}

Keywords: Anadenanthera macrocarpa (Benth) Brenan, vegetative propagation, mini-cutting, plant propagation, $A M F, B N F$.

\section{INTRODUÇÃO}

Entre os sistemas biológicos envolvendo planta e microrganismos, destacam-se as simbioses leguminosas-rizóbio formando as bactérias fixadoras de nitrogênio nodulíferas, de maior expressão econômica, e leguminosas-fungos micorrízicos arbusculares (FMAs) (SIVIERO et al., 2008). A dupla inoculação com rizóbio e FMAs durante o processo de produção de mudas é capaz de reduzir os custos com fertilizantes nitrogenados e fosfatados, além de conferir, às mudas, maior capacidade de absorção de nutrientes, induzindo aumento da produtividade (TIAN et al., 2003). Essas associações mutualistas constituem importante ligação entre os componentes bióticos e abióticos do solo, desempenhando papel fundamental na sobrevivência, no crescimento e desenvolvimento das plantas durante a fase de viveiro e após o plantio (BERBARA et al., 2006).

Diversas são as opções de tipos de substratos destinados à produção de mudas, sendo os mais utilizados em escala comercial os compostos orgânicos, que devem ser livres de organismos fitopatogênicos (XAVIER et al., 2009). No entanto, durante o processo de eliminação dos microrganismos patogênicos, também são eliminados os rizóbios e FMAs que podem favorecer o crescimento e estabelecimento das mudas após o plantio no campo (CARNEIRO, 1995; MOREIRA; SIQUEIRA, 2006).

A inoculação de FMAs e rizóbios no substrato pode contribuir para melhorar a qualidade das mudas, visto que as micorrizas auxiliam no crescimento da planta, pela melhoria na absorção de nutrientes, especialmente o fósforo, pelo aumento do volume de solo explorado e pelo aumento da tolerância a estresses bióticos e abióticos (KHADE; RODRIGUES, 2009; CHAER et al., 2011); no caso das leguminosas, os rizóbios vão atuar na fixação biológica do nitrogênio (MARTÍNEZ, 2009).
O angico-vermelho (Anadenanthera macrocarpa (Benth) Brenan) é uma leguminosa com reconhecida simbiose com FMAs e os rizóbios (PEREIRA et al., 1996), sendo os benefícios desses microrganismos na produção dessa espécie já comprovados em alguns estudos. Santos et al. (2008) observaram que o teor de $\mathrm{N}$ e $\mathrm{P}$ de mudas de angico-vermelho foi incrementado, assim como o crescimento das mudas, pela inoculação do FMAs e rizóbios nativos. Pereira et al. (1996) observaram que, além de efeitos diretos na nutrição fosfatada, a micorriza mostrou-se importante para a nutrição nitrogenada da espécie. Chaves et al. (2006), usando bagaço de cana-de-açúcar e torta de filtro de usina açucareira (3:2; V: V) como substrato, concluíram que a inoculação com rizóbio foi suficiente, não sendo necessária nenhuma fonte externa de $\mathrm{N}$.

A produção de mudas de angico-vermelho via seminal limita a produção comercial de mudas, já que as sementes do angico-vermelho são recalcitrantes (CARVALHO, 2003). Dessa forma, as técnicas de propagação vegetativa, entre elas a miniestaquia, vêm ao encontro dos objetivos de superação das dificuldades na produção de mudas, podendo ser utilizada para fins comerciais (XAVIER et al., 2009), assim como auxiliar na conservação de recursos genéticos florestais.

Para espécies do gênero Eucalyptus, há alguns estudos relacionando a utilização de rizobactérias no substrato com o aumento do enraizamento de miniestacas e seu crescimento após o enraizamento (MAFIA et al., 2005; ALFENAS et al., 2009; MAFIA et al., 2009). No entanto, para espécies nativas do Brasil, a utilização dos rizóbios e FMAs ainda necessita de estudos que relacionem a produção de mudas via propagação vegetativa com as relações simbiontes.

Outro fator que pode influenciar na qualidade da muda e no sucesso da associação mutualista é o material genético utilizado. Segundo Mankessi et al. (2009), 
flutuações na capacidade rizogênica são capazes de ocorrer mesmo entre genótipos estreitamente aparentados, de acordo com determinismo endógeno, o que influencia diretamente na qualidade da muda produzida.

Este estudo teve como objetivo avaliar a influência da inoculação com fungos micorrízicos arbusculares e de rizóbios no enraizamento, crescimento e nutrição das mudas de progênies de meios-irmãos de angicovermelho propagadas via miniestaquia.

\section{MATERIAL E MÉTODOS}

Foram utilizadas como minicepas mudas originadas da propagação via sementes de seis progênies de meiosirmãos de angico-vermelho (Anadenanthera macrocarpa), procedentes de seis municípios da Zona da Mata mineira (P1- Porto Firme, P12- Piranga, P17- Cajuri, P35- Santa Bárbara do Tugúrio, P45- Rio Pomba e P60- Guaraciaba). A seleção das matrizes e a coleta das sementes foram feitas pela Sociedade de Investigações Florestais - SIF/ UFV. As mudas e o estabelecimento do minijardim clonal foram feitos no Viveiro de Pesquisas do Departamento de Engenharia Florestal da Universidade Federal de Viçosa, em Viçosa, MG.

Das minicepas foram obtidas miniestacas com 10 cm de comprimento sem corte foliar. Imediatamente após coletadas e preparadas, as miniestacas foram estaqueadas em casa de vegetação climatizada (com umidade relativa do ar superior a $85 \%$ e temperatura entre 20 e $30^{\circ} \mathrm{C}$ ). Como recipientes, foram utilizados tubetes plásticos de $55 \mathrm{~cm}^{3}$ de capacidade, contendo como substrato o composto orgânico comercial Mecplant ${ }^{\circledR}$.

Utilizou-se um arranjo fatorial 4 x 6, constituído de quatro composições do substrato e seis progênies de meios-irmãos, dispostos em delineamento experimental de blocos ao acaso, com quatro repetições e parcela composta de 12 miniestacas. Foram testados quatro tratamentos: T1: composto pela suplementação de 8 $\mathrm{kg} \mathrm{m}^{-3}$ de superfosfato simples (SS) misturados ao substrato de enraizamento, sem adição de microrganismos; T2: composto pela suplementação de $4 \mathrm{~kg} \mathrm{~m}^{-3} \mathrm{de} \mathrm{SS} \mathrm{misturados}$ ao substrato de enraizamento sem adição de microrganismos; T3: composto pela suplementação de $4 \mathrm{~kg} \mathrm{~m}^{-3}$ de SS misturados ao substrato de enraizamento, sendo adicionados, a cada tubete, a $2 \mathrm{~cm}$ da superfície, $5 \mathrm{~mL}$ de suspensão aquosa contendo rizóbios; T4: composto pela suplementação de $4 \mathrm{~kg} \mathrm{~m}^{-3}$ de SS, sendo adicionados, a cada tubete, a $2 \mathrm{~cm}$ da superfície, $5 \mathrm{~mL}$ de suspensão aquosa contendo rizóbios e 5 g de solo contendo esporos e raízes colonizadas com os FMAs, contendo 100 esporos por tubete das espécies de Glomus clarum e Gigaspora margarita.

O tempo de permanência das miniestacas em casa de vegetação foi de 30 dias, sendo posteriormente aclimatadas em casa de sombra com $50 \%$ de sombreamento durante 10 dias e transferidas para área de pleno sol para crescimento até completarem 140 dias. Nos tratamentos T1 e T2, na saída de casa de vegetação foi feita uma adubação de cobertura, aplicandose $2 \mathrm{~mL} \mathrm{muda}^{-1} \mathrm{de}$ fosfato monoamônico $\left(2,0 \mathrm{~g} \mathrm{~L}^{-1}\right)$, e na saída da casa de sombra foram aplicados $5 \mathrm{~mL}$ muda $^{-1}$ do formulado NPK (10-05-30) $\left(6 \mathrm{~g} \mathrm{~L}^{-1}\right)$.

As avaliações feitas na saída da casa de vegetação (30 dias) e da casa de sombra (40 dias) foram relativas à porcentagem de sobrevivência das miniestacas e à porcentagem de miniestacas com raízes observadas na extremidade inferior do tubete. Aos 140 dias de idade, foram avaliados o percentual de sobrevivência, o percentual de enraizamento, a altura, o diâmetro de colo, o número de raízes, o número de estacas com nódulos, o número de nódulos, a massa de matéria seca de nódulos, a massa de matéria seca da parte aérea e da raiz e a porcentagem de raízes colonizadas por FMAs, bem como foi feita a análise foliar analítica de nitrogênio, fósforo e potássio.

Para efeito das avaliações, foram consideradas enraizadas as miniestacas com raízes superiores ou iguais a $0,5 \mathrm{~cm}$ e com emissão de brotações na parte aérea. Para a contagem do número de raízes, foram consideradas as raízes emitidas diretamente da base das miniestacas. Na medição da altura e do diâmetro de colo, foram consideradas as miniestacas com presença de raiz e de brotações, sendo a altura determinada com régua milimetrada do nível do substrato até a ponta da última folha, e o diâmetro de colo foi determinado ao nível do substrato, por um paquímetro de precisão. Para obtenção da massa de matéria seca, a parte aérea foi separada da parte radicular e seca em estufa a $55^{\circ} \mathrm{C}$ até massa constante. Nos tratamentos em que foi feita a inoculação com rizóbio, foi feita a contagem do número de nódulos em cada sistema radicular, sendo posteriormente separados da raiz para determinação da massa de matéria seca.

Os materiais secos da parte aérea foram moídos e peneirados para realização da análise química. Foram digeridos em solução nitroperclórica, sendo o teor de

Revista Árvore, Viçosa-MG, v.36, n.6, p.1027-1037, 2012 
$\mathrm{K}$ determinado por fotometria de chama, o de $\mathrm{N}$ pelo método de Kjeldahl e o P, colorimetricamente, pelo método da vitamina C, modificado por Braga e Defelipo (1974).

Para estimar a colonização por FMAs, as raízes das plantas foram lavadas em água corrente, descoradas em solução de $\mathrm{KOH} 10 \%$ e coradas com azul de tripano 0,05\% em lactoglicerol (GIOVANNETTI; MOSSE, 1980). A colonização foi estimada pelo método da contagem em placa quadriculada (KOSKE; GEMMA, 1989).

Os dados foram interpretados estatisticamente pela análise de variância e pelo teste de médias (teste de Tukey a $5 \%$ de probabilidade), utilizando-se o software Estatística 8.0.

\section{RESULTADOS}

Não houve interação entre as progênies e os tratamentos avaliados no substrato na produção de mudas propagadas via miniestaquia de $A$. macrocarpa para as características avaliadas na saída da casa de vegetação e na saída da casa de sombra. No entanto, houve diferenças entre as progênies para as características analisadas na saída da casa de vegetação e da casa de sombra (Tabela 1), sugerindo diferenças genéticas entre progênies quanto à capacidade de enraizamento e emissão de raízes adventícias das miniestacas.

Houve redução da sobrevivência na saída da casa de sombra das miniestacas, comparativamente à saída da casa de vegetação (Tabela 1). Entretanto, a porcentagem de miniestacas com raízes observadas na extremidade inferior do tubete aumentou. Na saída da casa de vegetação, as progênies apresentaram percentuais de sobrevivência e percentuais de raízes observadas na extremidade inferior do tubete superiores a $87,5 \%$ e $41,2 \%$, respectivamente. $\mathrm{O}$ baixo percentual de mudas com raízes observadas na extremidade inferior do tubete, comparado com a sobrevivência, indica que as estacas apresentavam raízes pequenas e com baixo volume na saída da casa de vegetação. Entretanto, na saída da casa de sombra as progênies exibiram percentuais de sobrevivência e raiz observadas na extremidade inferior do tubete superiores a 78,5\% e $60,8 \%$, respectivamente.

Quanto às características avaliadas aos 140 dias após o estaqueamento, observou-se interação entre progênie e composição do substrato nas mudas de A. macrocarpa para altura, diâmetro de colo e massa de matéria seca da parte aérea (Tabela 2). Os tratamentos aplicados no substrato influenciaram na porcentagem de enraizamento, número de raízes, concentração de $\mathrm{N}$ e P na parte aérea das mudas (Tabela 3 ).

Para o diâmetro de colo, observou-se diferença entre os tratamentos somente na progênie P60, tendo o tratamento T3 a maior média (1,99 mm) (Tabela 3). Entretanto, para altura foi observada diferença entre os tratamentos nas progênies P35 e P45, sendo o tratamento T1 superior aos demais, com média de 20,94 cme $21,25 \mathrm{~cm}$, respectivamente (Tabela 2). Os tratamentos que apresentaram as menores alturas foram o $\mathrm{T} 3 \mathrm{e} o$

Tabela 1 - Percentagem de sobrevivência (SOB) e percentagem de miniestacas com raízes observadas na extremidade inferior do tubete (ROEIT) de miniestacas de angico-vermelho (Anadenanthera macrocarpa), em função das diferentes progênies na saída da casa de vegetação e casa de sombra.

Table 1 - Survival percentage (SOB), roots percentage observed at the bottom of the container (ROEIT) of minicuttings of Anadenanthera macrocarpa, as a function of the progenies in the greenhouse exit and the shade house exit.

\begin{tabular}{|c|c|c|c|c|}
\hline \multirow{2}{*}{ Progênie/matriz } & \multicolumn{2}{|c|}{ Casa de vegetação } & \multicolumn{2}{|c|}{ Casa de sombra } \\
\hline & SOB $(\%)$ & ROEIT (\%) & $\operatorname{SOB}(\%)$ & ROEIT $(\%)$ \\
\hline $\mathrm{P} 1$ & $92,4 \mathrm{ab}$ & $43,5 \mathrm{~b}$ & 90,2 a & $60,8 \mathrm{c}$ \\
\hline $\mathrm{P} 12$ & $100,0 \mathrm{a}$ & 47,9 a & 97,9 a & 69,4 a \\
\hline $\mathrm{P} 17$ & $95,1 \mathrm{ab}$ & 51,9 a & 92,4 a & $71,5 \mathrm{a}$ \\
\hline P35 & 96,5 a & 50,0 a & 95,1 a & $65,3 \mathrm{ab}$ \\
\hline $\mathrm{P} 45$ & $87,5 \mathrm{~b}$ & $42,2 \mathrm{~b}$ & $78,5 \mathrm{~b}$ & $62,1 \mathrm{bc}$ \\
\hline P60 & $97,2 \mathrm{a}$ & $43,5 \mathrm{~b}$ & $91,0 \mathrm{a}$ & $66,4 \mathrm{ab}$ \\
\hline $\mathrm{CV}(\%)$ & 12 & 15 & 13 & 17 \\
\hline
\end{tabular}

*Médias seguidas de uma mesma letra entre progênies e em uma mesma condição de avaliação, não diferem entre si, pelo teste de Tukey a $5 \%$ de probabilidade.

Revista Árvore, Viçosa-MG, v.36, n.6, p.1027-1037, 2012 
Tabela 2 - Diâmetro de colo (DC), altura (ALT) e massa seca da parte aérea (MSPA) de miniestacas de Anadenanthera macrocarpa, aos 140 dias, em função das progênies (Prog.), e dos tratamentos (Trat.) referentes à concentração de fósforo no substrato e inoculação com rizóbio e fungos micorrízicos arbusculares.

Table 2 - Collar diameter (CD), height (ALT) and shoot dry mass (MSPA) of mini-cuttings of Anadenanthera macrocarpa, at 140 days, according to the progeny (Prog.) and treatments (Trat.) regarding the concentration of phosphorus and the presence of rhizobium and arbuscular mycorrhizae.

\begin{tabular}{|c|c|c|c|c|}
\hline Prog. & TRAT. $* *$ & $\mathrm{DC} \mathrm{mm}$ & ALT $\mathrm{cm}$ & MSPAg \\
\hline \multirow[t]{4}{*}{$\mathrm{P} 1$} & $\mathrm{~T} 1$ & $1,95 \quad \mathrm{Aa}^{*}$ & $20,00 \ldots \mathrm{Aa}$ & $0,39 \ldots$ Aa \\
\hline & $\mathrm{T} 2$ & $1,95 \ldots \mathrm{Aa}$ & $18,44 \ldots \mathrm{Aa}$ & $0,46 \ldots \mathrm{Aa}$ \\
\hline & T 3 & $1,84 \quad \mathrm{Ba}$ & $19,44 \ldots \mathrm{Aa}$ & $0,33 \ldots \mathrm{Aa}$ \\
\hline & $\mathrm{T} 4$ & $1,94 \mathrm{Aa}$ & $18,94 \ldots \mathrm{Ba}$ & $0,24 \ldots \mathrm{ABa}$ \\
\hline \multirow[t]{4}{*}{ P 12} & T 1 & $1,93 \ldots \mathrm{ABa}$ & $19,90 \ldots \mathrm{Aa}$ & $0,37 \ldots$ Aa \\
\hline & $\mathrm{T} 2$ & $1,84 \ldots \mathrm{Aa}$ & $18,48 \ldots \mathrm{Aa}$ & $0,40 \ldots \mathrm{Aa}$ \\
\hline & T 3 & $1,94 \ldots \mathrm{Aa}$ & $20,24 \ldots$ Aa & $0,32 \ldots \mathrm{Aa}$ \\
\hline & $\mathrm{T} 4$ & $1,90 \ldots \mathrm{Aa}$ & $18,54 \quad \mathrm{Ba}$ & $0,29 \ldots \mathrm{ABa}$ \\
\hline \multirow[t]{4}{*}{ P17 } & $\mathrm{T} 1$ & $1,82 \quad \mathrm{Ca}$ & $19,72 \ldots$ Aa & $0,31 \ldots$ Aa \\
\hline & $\mathrm{T} 2$ & $1,88 \ldots \mathrm{Aa}$ & $18,78 \ldots \mathrm{Aa}$ & $0,25 \ldots \mathrm{Aa}$ \\
\hline & T 3 & 1,95 Aa & $19,57 \ldots \mathrm{Aa}$ & $0,26 \ldots \mathrm{Aa}$ \\
\hline & $\mathrm{T} 4$ & $1,93 \quad \mathrm{Aa}$ & $20,89 \ldots \mathrm{Aa}$ & $0,27 \ldots \mathrm{ABa}$ \\
\hline \multirow[t]{4}{*}{ P35 } & $\mathrm{T} 1$ & $1,89 \ldots \mathrm{ABa}$ & $20,94 \ldots \mathrm{Aa}$ & $0,37 \ldots \mathrm{Aa}$ \\
\hline & $\mathrm{T} 2$ & $1,91 \ldots \mathrm{Aa}$ & $20,37 \ldots \mathrm{Aab}$ & $0,29 \ldots \mathrm{Aab}$ \\
\hline & T 3 & $1,93 \mathrm{Aa}$ & $19,36 . . \mathrm{ABbc}$ & $0,21 \ldots \mathrm{Ab}$ \\
\hline & $\mathrm{T} 4$ & $1,93 \ldots \mathrm{Aa}$ & $19,08 \ldots \mathrm{Bc}$ & $0,23 \ldots \mathrm{Ab}$ \\
\hline \multirow[t]{4}{*}{$\mathrm{P} 45$} & $\mathrm{~T} 1$ & $1,93 \mathrm{ABa}$ & $21,25 \ldots \mathrm{Aa}$ & $0,39 \ldots \mathrm{Aa}$ \\
\hline & $\mathrm{T} 2$ & 1,93 Aa & $17,40 \ldots \mathrm{Abc}$ & $0,35 \ldots$ Aa \\
\hline & T 3 & $1,98 \ldots \mathrm{Aa}$ & $16,87 \ldots \mathrm{Bc}$ & $0,29 \ldots \mathrm{Aa}$ \\
\hline & $\mathrm{T} 4$ & $1,98 \ldots \mathrm{Aa}$ & $19,11 \ldots \mathrm{Bb}$ & $0,23 \quad \mathrm{ABa}$ \\
\hline \multirow[t]{4}{*}{ P60 } & $\mathrm{T} 1$ & $1,96 \ldots \mathrm{Aab}$ & $19,17 \ldots \mathrm{Aa}$ & $0,16 \ldots \mathrm{Ab}$ \\
\hline & $\mathrm{T} 2$ & $1,97 \ldots \mathrm{Aab}$ & $19,78 \ldots \mathrm{Aa}$ & $0,31 \ldots \mathrm{Aab}$ \\
\hline & T 3 & $1,99 \ldots$ Аа & $20,33 \ldots \mathrm{Aa}$ & 0,27 Aab \\
\hline & $\mathrm{T} 4$ & $1,94 \ldots \mathrm{Ab}$ & $19,53 \ldots \mathrm{Ba}$ & 0,41. .Aa \\
\hline
\end{tabular}

$\mathrm{CV}(\%)$

17

19

22

* Médias seguidas de uma mesma letra minúscula dentro de cada progênie e médias seguidas de uma mesma letra maiúscula dentro do mesmo tratamento entre as progênies não diferem entre si pelo teste de Tukey a 5\% de probabilidade.

** T1: $8 \mathrm{~kg} \mathrm{~m}^{-3}$ de superfosfato simples misturados ao substrato de enraizamento, sem adição de microrganismos; $\mathrm{T} 2: 4 \mathrm{~kg} \mathrm{~m}^{-3}$ de superfosfato simples misturados ao substrato de enraizamento sem adição de microrganismos; $\mathrm{T} 3: 4 \mathrm{~kg} \mathrm{~m}^{-3}$ de superfosfato simples misturado ao substrato $+5 \mathrm{~mL}$ de solução salina contendo rizóbio; T4: $4 \mathrm{~kg} \cdot \mathrm{m}^{-3}$ de superfosfato simples $+5 \mathrm{~mL}$ de solução salina contendo rizóbio e 5 g de solo contendo esporos e raízes colonizadas com os FMAs.

Tabela 3 - Percentagem de sobrevivência de miniestacas, número de raiz (NR), concentração de nitrogênio (N) e fósforo (P) na parte aérea de miniestacas de seis progênies de Anadenanthera macrocarpa aos 140 dias após o estaqueamento, em função dos tratamentos relativos à concentração de fósforo no substrato e inoculação com rizóbio e fungos micorrízicos arbusculares.

Table 3 - Percentage of survival of mini-cuttings, root number $(N R)$, concentration of nitrogen $(N)$ and phosphorus $(P)$ in shoots of mini-cuttings of six progenies of Anadenanthera macrocarpa, at 140 days after staking, as a function of treatments $(T 1, T 2, T 3$ and $T 4 * *)$ regarding phosphorus concentration on the substrate, and inoculation with rhizobium and arbuscular mycorrhizae fungi

\begin{tabular}{ccccc}
\hline Tratamento & SOB $(\%)$ & NR & N $(\mathrm{g} / \mathrm{kg})$ & $\mathrm{P}(\mathrm{g} / \mathrm{kg})$ \\
\hline T 1 & $48,33 \mathrm{~b} *$ & $1,76 \mathrm{bc}$ & $31,4 \mathrm{a}$ & $17,6 \mathrm{a}$ \\
T 2 & $51,67 \mathrm{~b}$ & $1,57 \mathrm{c}$ & $26,1 \mathrm{~b}$ & $15,3 \mathrm{ab}$ \\
T3 & $67,22 \mathrm{a}$ & $2,01 \mathrm{a}$ & $18,8 \mathrm{c}$ & $13,0 \mathrm{~b}$ \\
T 4 & $72,22 \mathrm{a}$ & $1,95 \mathrm{ab}$ & $18,3 \mathrm{c}$ & $15,6 \mathrm{ab}$ \\
\hline
\end{tabular}

$\mathrm{CV}(\%)$

15

16

20

18

*Médias seguidas de uma mesma letra minúscula na linha não diferem entre si pelo teste de Tukey a 5\% de probabilidade.

** T1: $8 \mathrm{~kg} \mathrm{~m}^{-3}$ de superfosfato simples misturados ao substrato de enraizamento, sem adição de microrganismos; T2: $4 \mathrm{~kg} \mathrm{~m}^{-3}$ de superfosfato simples misturados ao substrato de enraizamento sem adição de microrganismos; T3: $4 \mathrm{~kg} \mathrm{~m}^{-3}$ de superfosfato simples misturados ao substrato $+5 \mathrm{~mL}$ de solução salina contendo rizóbio; T4: $4 \mathrm{~kg} \cdot \mathrm{m}^{-3}$ de superfosfato simples +5 mL de solução salina contendo rizóbio e 5 g de solo contendo esporos e raízes colonizadas com os FMAs. 
T4. Com relação à massa de matéria seca da parte aérea, houve diferença entre os tratamentos na progênie P35, com maiores médias no tratamento T1 (0,37 g) e na progênie P60, sendo o tratamento T4 superior aos demais, com média de 0,41 g de massa seca da parte aérea (Tabela 2).

As maiores porcentagens de sobrevivência das miniestacas aos 140 dias após o estaqueamento foram observadas nos tratamentos T3 $(67,22 \%)$ e T4 $(72,22 \%)$ (Tabela 3). Para número de raízes, esses tratamentos apresentam médias de 2,01 e 1,95, respectivamente, sendo superiores aos demais (Tabela 3). Entretanto, para concentração de nitrogênio na parte aérea os tratamentos 3 e 4 apresentaram médias próximas a $18 \mathrm{~g} \mathrm{~kg}^{-1}$, inferiores às médias dos tratamentos $1 \mathrm{e}$ 2, com $31 \mathrm{~g} \mathrm{~kg}^{-1}$ e $26 \mathrm{~g} \mathrm{~kg}^{-1}$, respectivamente (Tabela 3). Quanto ao teor de fósforo na parte aérea, o tratamento

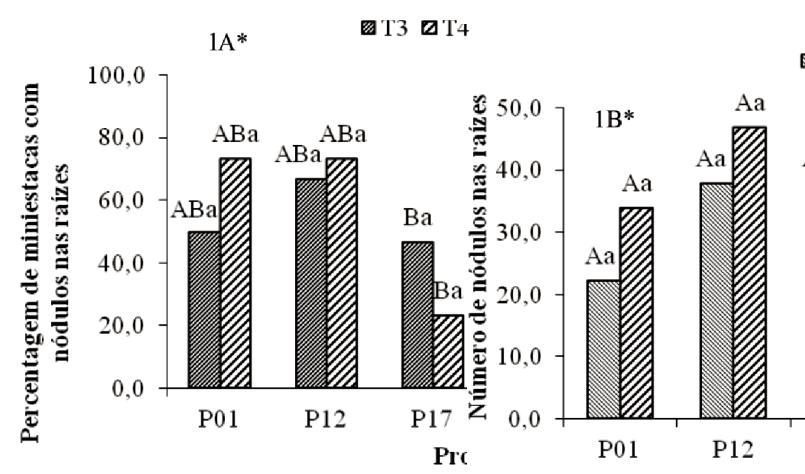

3 foi inferior aos demais, com média de $13 \mathrm{~g} \mathrm{~kg}^{-1}$, tendo os demais tratamentos médias superiores a $15 \mathrm{~g} \mathrm{~kg}^{-1}$ (Tabela 3).

A inoculação com rizóbio, nos tratamentos T3 e T4, foi efetiva para nodulação das raízes (Figura 1A). A porcentagem de nodulação nas raízes das miniestacas variou entre as progênies, sendo observados maiores percentuais nas progênies P35 e P60, com 80\% e 83,3\%, respectivamente, e a menor porcentagem na progênie P17, com 39\% das miniestacas apresentando nódulos nas raízes. O número de nódulos nas raízes colonizadas foi superior a 29 (Figura 1B), sendo observada maior média na progênie P12 $(46,99)$. A massa de matéria seca dos nódulos variou de 0,04 a 0,08 g (Figura 1C).

A colonização das raízes das progênies de angicovermelho por FMAs no tratamento T4 variou de $13,16 \%$ a 23,37\% (Figura 2). Ressalta-se a maior colonização

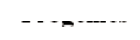

田3 $0 \mathrm{~T} 4$

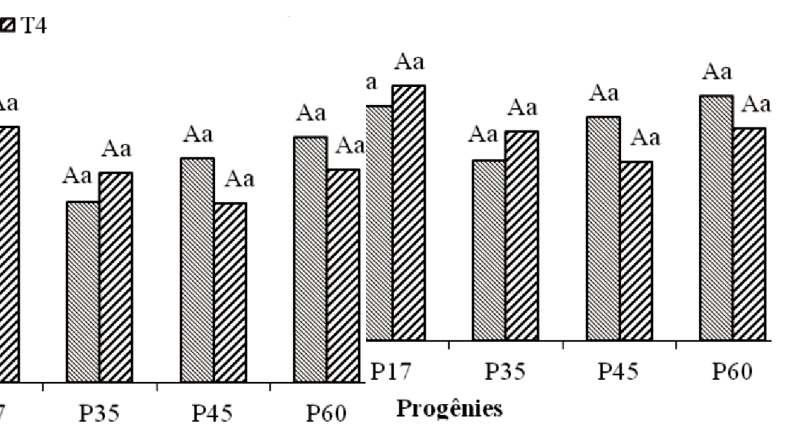

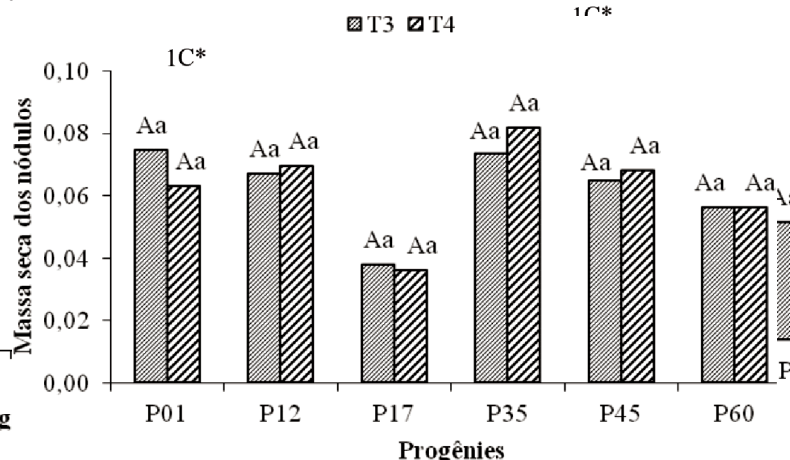

Figura 1 - Percentagem de mudas de Anadenanthera macrocarpa, propagadas via miniestaquia, com nódulos nas raízes (1A), número de nódulos presentes nas raízes (1B) e massa seca de nódulos (1C) aos 140 dias após o estaqueamento, em função das progênies avaliadas e dos tratamentos $\mathrm{T} 3\left(4 \mathrm{~kg} \mathrm{~m}^{-3}\right.$ de superfosfato simples e rizóbio adicionados ao substrato) e T4 (4 $\mathrm{kg} \mathrm{m}^{-3}$ de superfosfato simples, rizóbio e FMA adicionados ao substrato).

Figure 1 - Percentage of Anadenanthera macrocarpa seedlings propagated via mini-cuttings, with nodules on the roots (1A), number of nodules present in the roots (1B) and dry weight of nodules (1C), at 140 days after staking, as function of the progeny evaluated and T3 $\left(4 \mathrm{~kg} \mathrm{~m}^{-3}\right.$ and SS rhizobium added to the substrate) and T4 (4 $\mathrm{kg}$ $m^{-3} S S, A M F$ and rhizobium added to the substrate).

Revista Árvore, Viçosa-MG, v.36, n.6, p.1027-1037, 2012 


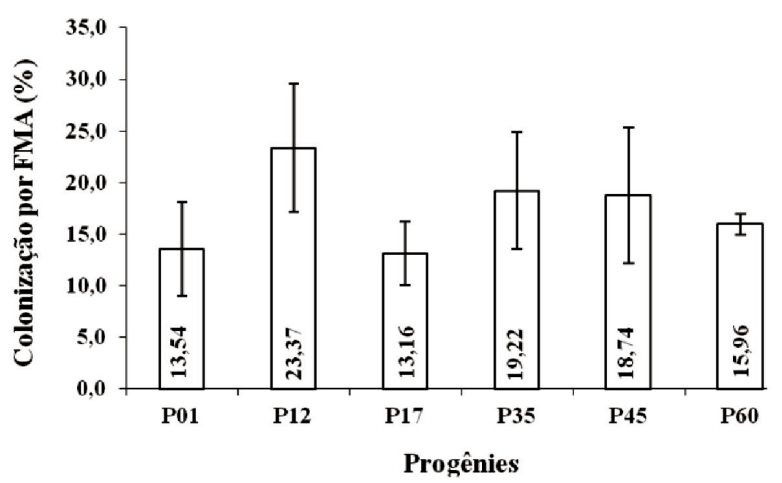

Figura 2 - Percentagem de colonização por FMA nas raízes de mudas de Anadenanthera macrocarpa propagadas via miniestaquia, aos 140 dias após o estaqueamento, em função das progênies avaliadas e do tratamento T4 (4 $\mathrm{kg} \mathrm{m}^{-3}$ de SS, rizóbio e FMA adicionados ao substrato). Barras verticais indicam o desvio padrão da média.

Figure 2 - Percentage of colonization by AMF in the roots of seedlings propagated via mini-cuttings Anadenanthera macrocarpa, at 140 days after staking, as function of progenies and T4 ( $4 \mathrm{~kg} \mathrm{~m}^{-3} \mathrm{SS}$, AMF and rhizobium added to the substrate). Vertical bars indicate standard deviations of the mean.

observada na progênie P12, indicando especificidade do genótipo dessa progênie em realizar a associação micorrízica. Nas plantas não inoculadas com FMA, não foi observada colonização micorrízica.

\section{DISCUSSÃO}

A sobrevivência e enraizamento das miniestacas na saída da casa de vegetação e da casa de sombra não foram influenciados pelo nível de fertilização do substrato ou pela inoculação dos microrganismos em razão, provavelmente, de as miniestacas, nesse primeiro momento, estarem utilizando reservas internas para a formação do sistema radicular. A mobilização de nutrientes minerais durante a iniciação radicular é diferente da mobilização que ocorre durante o crescimento e desenvolvimento da raiz, sendo mais acentuada nesta última fase (CUNHA et al., 2009). Assim, a influência da nutrição mineral na iniciação radicular é altamente dependente dos níveis iniciais dentro daquela porção da estaca onde as raízes serão formadas (MALAVASI, 1994). Segundo Haissing (1986), a aplicação de nutrientes minerais na base das estacas geralmente não é necessária durante a fase de indução, visto os nutrientes endógenos serem basipetamente transportados a partir dos brotos.

O estado nutricional da planta-matriz, que fornece os propágulos para o enraizamento de estacas, é fator determinante no sucesso da propagação vegetativa pela miniestaquia, tendo em vista que o estado nutricional determinará a quantidade de carboidratos, auxinas, entre outros compostos metabólicos, fundamentais à iniciação radicial e à velocidade com que ela ocorre (MALAVASI, 1994; HIGASHI et al., 2004; XAVIER et al., 2009). Assim, especial atenção deve ser dada à nutrição da planta-matriz, visando atender às exigências nutricionais requeridas no processo de rizogênese adventícia.

A maior mortalidade das miniestacas observada na saída da casa de sombra, quando comparada à casa de vegetação, Tabela 1, pode ter ocorrido em função de a casa de vegetação proporcionar maior controle das condições ambientais, o que não ocorre na casa de sombra, por ser um ambiente destinado à aclimatação das miniestacas enraizadas. Assim, as miniestacas sem o sistema radicular ou com sistema radicular incompleto podem não sobreviver na casa de sombra em virtude do estresse causado pelas condições ambientais adversas (WENDLING; XAVIER, 2005; BRONDANI et al., 2010).

O considerável aumento do percentual de miniestacas com raízes observado na extremidade inferior do tubete, na saída da casa de sombra, está provavelmente relacionado ao fato de a indução do enraizamento ter ocorrido em casa de vegetação e após essa etapa ter ocorrido apenas no crescimento das raízes até a extremidade inferior do tubete. Segundo Ferreira et al. (2004), independentemente de os propágulos estarem na casa de enraizamento ou na casa de sombra, o índice de enraizamento não será alterado em razão de as estacas já estarem com as raízes formadas.

As respostas diferenciadas entre as progênies às características analisadas na saída da casa de vegetação e da casa de sombra (Tabela 1) provavelmente tenham ocorrido em razão de diferenças genéticas entre as progênies. Assim, as diferenças observadas podem advir do controle genético ou, mesmo, das diferenças entre ritmos endógenos da planta relacionados a fatores fisiológicos e morfológicos, pois flutuações na capacidade rizogênica são capazes de ocorrer mesmo

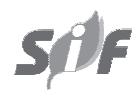

Revista Árvore, Viçosa-MG, v.36, n.6, p.1027-1037, 2012 
entre genótipos estreitamente aparentados, de acordo com o determinismo endógeno (MANKESSI et al., 2009).

Com as avaliações feitas na saída da casa de vegetação e da casa de sombra, observa-se que os tratamentos utilizados não tiveram influência direta na formação de raízes adventícias nas progênies de A. macrocarpa estudadas. No entanto, os resultados das características avaliadas a pleno sol (140 dias após o estaqueamento), em razão de as miniestacas estarem com o sistema radicular formado e bem desenvolvido e necessitando de nutrientes para o crescimento da parte aérea, indicaram que os tratamentos apresentaram importância significativa no crescimento das plantas. Mafia et al. (2005, 2009) observaram que isolados de rizobactérias não influenciaram diretamente no enraizamento de estacas de eucalipto, entretanto foi verificado pelos autores influência direta dos isolados rizobacterianos no crescimento das plantas após o enraizamento das estacas.

Os resultados relacionados à presença de nódulos e ao número de nódulos indicam que a inoculação com rizóbio pode ser feita com o estaqueamento das miniestacas, e os rizóbios permaneceram ativos até a formação do sistema radicular, não sendo lixiviados com o sistema de irrigação adotado. Todas as plantas, avaliadas aos 140 dias, nos tratamentos em que houve inoculação com rizóbios, estavam colonizadas, mostrando a eficiência da inoculação concomitantemente ao estaqueamento.

Quanto ao diâmetro de colo, houve diferença entre os tratamentos somente na progênie P60, a altura teve diferenças entre os tratamentos nas progênies P35 e P45 e a massa de matéria seca da parte aérea apresentou diferença nas progênies P35 e P60 (Tabela 2). Isso evidenciou que os tratamentos com microrganismos foram eficientes para essas características avaliadas, apresentando médias semelhantes às dos tratamentos em que foram utilizados nitrogênio e fósforo na adubação de cobertura. Esse resultado é semelhante ao encontrado por Patreze e Cordeiro (2004) em Anadenanthera colubrina, Mimosa bimucronata e Parapiptadenia rigida, por Zai et al. (2007) em Prunus maritima e por Siviero et al. (2008) em paricá.

Para concentração de nitrogênio na parte aérea, os tratamentos utilizando os microrganismos apresentaram médias inferiores, apesar de terem mostrado

Revista Árvore, Viçosa-MG, v.36, n.6, p.1027-1037, 2012 elevado número de nódulos. Resultado semelhante foi encontrado por Patreze e Cordeiro (2004) em P. rigida e A. colubrina, e nessas espécies os referidos autores observaram poucos nódulos. Segundo eles, a baixa concentração de nitrogênio nos tecidos pode ser devida a vários fatores, como deficiência de $\mathrm{P}$ e $\mathrm{N}$, rizóbio ineficaz ou efeito diluição (com mais $\mathrm{P}$, maior crescimento e diluição do N).

O fósforo tem influência na iniciação, crescimento e funcionamento dos nódulos, pois a atividade da nitrogenase é dependente de ATP (SPRENT, 2001; SIVIEIRO et al., 2008). A adição de adubos nitrogenados tem efeito adverso na fixação biológica pela diminuição de disponibilidade de oxigênio na respiração nodular e limitação de carboidratos ao metabolismo do nódulo (DENISON; HARTER, 1995). Estudos realizados por Stephens e Neyra (1983) evidenciaram que a adição de nitrogênio a plantas de soja na forma de $\mathrm{KNO}_{3}$ decresce a atividade da nitrogenase em mais de $50 \%$. Isso ocorre porque o nitrato e o nitrito acumulados em nível nodular inibem a fixação de nitrogênio pela diminuição da disponibilidade de energia ao bacteroide.

Outro fator a ser considerado quando se discutem a atividade e a eficiência dos rizóbios são o tamanho e morfologia dos nódulos (SANCHEZ-DIAZ et al., 1990; PATREZE; CORDEIRO, 2004). Os nódulos encontrados neste estudo eram pequenos e apresentavam baixa massa de matéria seca, provavelmente porque a interação entre planta e microrganismo estava no início, tendo pouco aporte de $\mathrm{N}$ sendo fixado, além de a bactéria competir com a planta por nutrientes e carboidrato.

As maiores médias de porcentagem de sobrevivência e número de raízes aos 140 dias nos tratamentos inoculados com o FMA e, ou, o rizóbio, apesar da não constatação da influência dos microrganismos na formação do sistema radicular em casa de vegetação e casa de sombra, indicaram que esses simbiontes influenciam diretamente na sobrevivência das plantas após o enraizamento e que a associação simbiótica entre $A$. macrocarpa e rizóbio e, ou, FMAs é eficiente, em comparação com os demais tratamentos, na produção de mudas com melhores condições de sobrevivência ao longo do tempo. Resposta semelhante também foi obtida por Tian et al. (2003) em Robinia pseudoacacia, atribuída aos benefícios advindos da simbiose entre planta e microrganismos, principalmente em relação à absorção de nutrientes. 
A colonização por FMAs encontrada (13 a 23\%) está dentro do esperado. Patreze et al. (2004) obtiveram colonização em A. colubrina relativamente baixa (0 - 14\%) quando comparada com os resultados deste trabalho. Entretanto, Carneiro et al. (1998) encontraram resultados semelhantes aos apresentados neste estudo, com plantas de A. falcata (20\%-49\% de colonização) em condições de campo, mas, em $A$. peregrina em viveiro, os autores observaram de $1 \%$ a $19 \%$ de colonização. Além de fatores nutricionais, a baixa taxa de infecção pode estar associada à especificidade entre a planta hospedeira e os FMAs, já que, em algumas progênies, a exemplo da P12, foi observado valor de colonização de $23 \%$, enquanto na progênie 17 esse valor foi de $13 \%$.

Os resultados da concentração de fósforo na parte aérea indicaram que os FMAs contribuíram para a absorção desse nutriente, evidenciando-se a importância dos FMAs na absorção do fósforo. Zai et al. (2007) também encontraram altos níveis de fósforo na parte aérea das plantas de Prunus maritima inoculadas com FMAs. Em P. rigida, Patreze e Cordeiro (2004) verificaram resultado semelhante.

Durante a fase de desenvolvimento da raiz e crescimento da parte aérea, a planta necessita de maior aporte de nutrientes (CUNHA et al., 2009). Para o crescimento e estabelecimento de diversas espécies arbóreas, a dupla inoculação rizóbio/FMA parece ser procedimento vantajoso, favorecendo, por exemplo, a produção de biomassa em razão da maior absorção e fixação de nutrientes (GROSS et al., 2004). Neste estudo, a dupla inoculação com rizóbio e FMA apresentou médias superiores para porcentagem de enraizamento, diâmetro de colo e massa de matéria seca da parte aérea, confirmando o efeito benéfico da dupla inoculação para A. macrocarpa. Resultado semelhante foi encontrado por Friori et al. (1999) estudando as subfamílias Caesalpinioideae, Mimosoideae e Papilionoideae. Em paricá, Siviero et al. (2008) também observaram que a dupla inoculação rizóbio/FMA apresentou melhores resultados, tanto no viveiro quanto no campo.

As diferenças entre progênies para diâmetro do colo, altura, massa de matéria seca da parte aérea e massa de matéria seca de nódulos podem estar relacionadas com certa especificidade tanto do rizóbio quanto do FMA nas progênies estudadas. Mafia et al. (2009) observaram que diferenças no crescimento entre clones ocorreu em razão de certa especificidade de isolados de rizóbio. Segundo esses autores, um isolado pode promover o crescimento de uma espécie e ser ineficaz em outras. Têm sido relatadas diferenças na quantidade e qualidade dos exsudados radiculares de diferentes espécies vegetais, bem como de cultivares e genótipos da mesma espécie em razão da especificidade tanto dos rizóbios quanto dos FMAs (SHISHIDO e CHANWAY, 1999; FRIONI et al., 1999; MATSUMOTO et al., 2005; DRUEGE et al., 2006).

A utilização da associação entre rizóbio/FMA no crescimento de mudas de A. macrocarpa em campo pode ser favorecida em razão de essa associação ocorrer em condições naturais, proporcionando bom desenvolvimento da planta e auxiliando, em muitos casos, a adaptação a ambientes estressantes (PEREIRA et al., 1996; CHAVES et al., 2006; SILVA et al., 2009). Assim, a inoculação com rizóbio e FMAs em mudas de A. macrocarpa no viveiro pode diminuir gastos com fertilizantes, além de contribuir para um bom desenvolvimento da planta.

\section{CONCLUSÕES}

A inoculação com rizóbio e fungos micorrízicos arbusculares aumenta a sobrevivência de mudas de A. macrocarpa produzidas por estaquia.

A associação das plantas de A. macrocarpa com fungos micorrízicos arbusculares e rizóbios auxilia na absorção de fósforo e nitrogênio, respectivamente.

\section{REFERÊNCIAS}

AlfenAS, A. C. et al. Clonagem e doenças do eucalipto. 2.ed. Viçosa, MG: Universidade Federal de Viçosa, 2009. 500p.

BERBARA, R. L. L.; SOUZA, F. A.; FONSECA, H. M. A. C. Fungos micorrízicos arbusculares: Muito além da nutrição. In: FERNANDES, M. S. (Ed.). Nutrição mineral de plantas. Viçosa, MG: Sociedade Brasileira de Ciência do Solo, 2006. p.53-88.

BRAGA, J. M.; DEFELIPO, B. V. Determinação espectrofotométrica de fósforo em extratos de solo e material vegetal. Revista Ceres, v.21, n.1, p.73-85, 1974.

Revista Árvore, Viçosa-MG, v.36, n.6, p.1027-1037, 2012 
BRONDANI, G. E. et al. Aplicação de IBA para o enraizamento de miniestacas de Eucalyptus benthamii Maiden \& Cambage x Eucalyptus dunnii Maiden. Acta Scientiarum

Agronomy, v.32, n.4, p.667-674, 2010.

CARnEIRO, J. G. A. Produção e controle de qualidade de mudas florestais. Curitiba: UFPR/FUPEF, 1995. 451p.

CARNEIRO, M. A. C. et al. Micorriza arbuscular em espécies arbóreas e arbustivas nativas de ocorrência no sudeste do Brasil. Cerne, v.4, n.1, p.129-145, 1998.

CARVALHO, P. E. R. Espécies arbóreas brasileiras. Colombo: Embrapa-CNPF/Brasilia, D.F.: Embrapa-SPI, 2003. 1039p.

CHAER, G. M. et al. Nitrogen-fixing legume tree species for the reclamation of severely degraded lands in Brazil. Tree Physiology, v.31, p, n.2, p.139-149, 2011.

CHAVES, L. L. B.; CARNEIRO, J. G. A.; BARROSO, D. G. Crescimento de mudas de angico- vermelho produzidas em substrato fertilizado, constituído de resíduos agroindustriais. Revista Scientia Forestalis, n.72, p.49-56, 2006.

CUNHA, A. C. M. C. M. et al. Papel da nutrição mineral na formação de raízes adventícias em plantas lenhosas. Pesquisa Florestal Brasileira, n.58, p.37-47, 2009.

DENISON, R. F.; HARTER, B. L. Nitrate Effects on Nodule Oxygen Permeability and Leghemoglobin (Nodule Oximetry and Computer Modeling).

Plant Physiology, v. 107, v.4,p.1355-1364, 1995.

DRUEGE, U. et al. Rooting and vitality of poinsettia cuttings was increased by arbuscular mycorrhiza in the donor plants. Mycorrhiza, v.17, n.1, p.67-72, 2006.

FERREIRA, E. M. et al. Determinação do tempo ótimo do enraizamento de miniestacas de clones de Eucalyptus spp. Revista Árvore, v.28, n.2, p.183-187, 2004.

FRIONI, L.; MINASIAN, H.; VOLFOVICZ, R. Arbuscular mycorrhizae and ectomycorrhizae in native tree legumes in Uruguay. Forest Ecology and Management, v.115, n.1, p.41-47, 1999.
GIOVANNETTI, M.; MOSSE, B. An evaluation of techniques for measuring vesicular arbuscular mycorrhizal infection in roots. New

Phytologist, v.84, n.3, p.89-500, 1980.

GROSS, E.; CORDEIRO, L.; CAETANO, F. H. Nodulação e micorrização em Anadenanthera peregrina var. falcata em solo de cerrado autoclavado e não autoclavado. Revista Brasileira de Ciência do Solo, v.28, n.1, p.95-101, 2004.

HAISSING, B. E. Metabolic processes in adventitious rooting of cuttings. In: JACKSON, M. B. (Ed.). New root formation in plants and cuttings. Dordrecht: Martinus Nijhoff, 1986. p.141-189.

HIGASHI, E. N.; SILVEIRA, R. L. V. A.; GONÇALVES, A. N. Nutritional monitoring and fertilization in clonal macro, mini, and microgardens. In: GONÇALVES, J. L. M.; BENEDETI, V. (Ed.). Forest nutrition and fertilization. Piracicaba: IPEF, 2004. p.195-221.

KHADE, S. W.; RODRIGUES, B. F. Applications of arbuscular mycorrhizal fungi in agroecosystems. Tropical and Subtropical Agroecosystems, v.10, n.3, p.337-354, 2009.

MAFIA, R. G. et al. Root colonization and interaction among growth promoting rhizobacteria isolates and eucalypts species. Revista Árvore, v.33, n.1, p.1-9, 2009.

MAFIA, R. G. et al. Crescimento de mudas e produtividade de minijardins clonais de eucalipto tratados com rizobactérias selecionadas. Revista Árvore, v.29, n.6, p.843-851, 2005.

MALAVASI, U. C. Macropropagação vegetativa de coníferas - perspectivas biológicas e operacionais. Floresta e Ambiente, v.1, n.1, p.131-35, 1994.

MANKESSI, F. et al. In vitro rooting of genetically related Eucalyptus urophylla $\times$ Eucalyptus grandis clones in relation to the time spent in culture. Trees, v.23, n.5, p.931-940, 2009. 
MARTÍNEZ, E. R. Coevolution in Rhizobiumlegume symbiosis. DNA Cell Biol, v.28, p.60-70, 2009.

MATSUMOTO, L. S. et al. Interactions among functional groups in the cycling of carbon, nitrogen and phosphorus in the rhizosphere of three successional species of tropical woody trees. Applied Soil Ecology, v.28, n.1, p.57-65, 2005.

MOREIRA, F. M. S.; SIQUEIRA, J. O. Microbiologia e bioquímica do solo. 2.ed. Lavras: Universidade Federal de Lavras, 2006. 729p.

PATREZE, C. M.; CORDEIRO, L. Nitrogen-fixing and vesicular-arbuscular mycorrhizal symbioses in some tropical legume trees of tribe Mimoseae. Forest Ecology and Management, v.196, n.7, p.275-285, 2004.

PEREIRA, E. G. et al. Efeitos da micorriza e do suprimento de fósforo na atividade enzimática e na resposta de espécies arbóreas ao nitrogênio.

Revista Brasileira de Fisiologia

Vegetal, v.8, n.1, p.59-65, 1996.

SANCHEZ-DIAZ, M. et al. Effect of water stress on photosynthetic activity in the MedicagoRhizobium-Glomus symbiosis. Plant Science, v.71, n.2, p.215-221, 1990.

SANTOS, D. R. et al. Micorriza e rizóbio no crescimento e nutrição em $\mathrm{N}$ e $\mathrm{P}$ de mudas de angico-vermelho. Revista Caatinga, v.21, n.1, p.76-82, 2008.

SHISHIDO, M.; CHANWAY, C. P. Spruce growth response specificity after treatment with plant growth promoting Pseudomonas. Canadian Journal of Botany, v.77, n.1, p.22-31, 1999.
SILVA, R. F. et al. Ocorrência de fungos micorrízicos em espécies florestais na região central do estado do Rio Grande do Sul. Revista Brasileira de Agrociência, v.15, n.1-4, p.65-70, 2009.

SIVIERO, A. M. et al. Interaction among Nfixing bacteria and AM fungi in Amazonian legume tree (Schizolobium amazonicum) in field conditions. Applied Soil Ecology, v.39, n.36, p.144-152, 2008.

SPRENT, J. I. Nodulation in legumes. Kew: Royal Botanic Gardens, 2001. 146p.

STEPHENS, B. D.; NEYRA, C. A. Nitrate e nitrite reduction in relation to nitrogenase activity in soybean nodules and Rhizobium japonicum bacteroids. Plant Physiology, v.71, n.4, p.731-735, 1983.

TIAN, C. et al. Effect of inoculation with ecto and arbuscular mycorrhizae and Rhizobium on the growth and nitrogen fixation by black locust, Robinia pseudoacacia. New Forests, v.25, n.2, p.125-131, 2003.

WENDLING, I.; XAVIER, A. Influência do ácido indolbutírico e da miniestaquia seriada no enraizamento e vigor de miniestacas de clones de Eucalyptus grandis. Revista Árvore, v.29, n.6, p.921-930, 2005.

XAVIER, A.; WENDLING, I.; SILVA, R. L. Silvicultura clonal - princípios e técnicas. Viçosa, MG: Universidade Federal de Viçosa, 2009. 272p.

ZAI, X. et al. Effects of arbuscular mycorrhizal fungi on the rooting and growth of beach plum (Prunus maritima) cuttings. Journal of

Horticultural Science \&

Biotechnology, v.82, n.6, p.863-866, 2007. 
